\title{
LO QUE NO HACEN LOS MEJORES PROFESORES UNIVERSITARIOS
}

\section{WHAT NOT MAKE THE BEST PROFESSORS}

Carlos Iborra: Universidad de Valencia (España)

carlos.iborra@uva.es

\section{CURRÍCULUM VITAE}

Profesor de la Universidad de Valencia. Pertenece al Departamento de Matemáticas para la Economía y la Empresa en la Facultad de Economía de dicha Universidad.

\section{RESUMEN}

La Universidad de Valencia ha distribuido el libro Lo que hacen los mejores profesores universitarios, para que los profesores traten de adoptar las ideas que en él se exponen. Hace referencia, entre otras cosas, a que los mejores profesores universitarios no siguen cronogramas ni se someten a un temario prefijado, o no se coordinan con otros profesores que impartan su misma asignatura para, por ejemplo, evaluar a sus alumnos con exámenes comunes con los grupos impartidos por otros profesores. Tampoco están obligados a poner notas de 0 a 10 con una cifra decimal, $y$, por supuesto, no tienen prohibido examinar a sus alumnos.

\section{PALABRAS CLAVE}

Universidad - Profesor - Alumno - Exámenes - Evaluar 


\section{ABSTRACT}

The University of Valencia has distributed the book What the best academics, for teachers to try to adopt the ideas in it are exposed. Refers, inter alia, that the best academics do not follow schedules and are subject to a predetermined agenda, or not coordinated with other teachers to impart the same subject, for example, assess their students with common tests with groups taught by other teachers. Nor are required to bring notes from 0 to 10 with one decimal place, and, of course, are not prohibited from examining their students.

\section{KEY WORDS}

University - Teacher - Student - Testing - Evaluate

\section{TEXTO:}

Hace unos días, todas las profesoras y todos los profesores de la Universidad de Valencia hemos recibido una carta de la rectora o del rector, la señora doña Francisca o el señor don Francisco Tomás Vert, donde, entre solecismos como los que aquí parodio (solecismos que, si son deplorables en cualquier caso, más lo son si los suscribe un catedrático, al que cabría suponer cierta cultura general) nos invita a leer el libro Lo que hacen los mejores profesores universitarios, de Ken Bain, que la universidad ha distribuido gratuitamente entre todo su personal docente, con el objetivo de "que nos pueda servir a todos y todas [sic] para, conjuntamente, pensar, debatir y mejorar nuestra enseñanza". Pensemos, pues, y debatamos, y no sólo todos y todas, sino otros y otras también: cuantos y cuantas más, mejor. 
Habría disfrutado de su lectura si no me hubiera acompañado en todo momento la tristeza de pensar cuán difícil, si no imposible en muchos casos, es que un profesor trate de adoptar las ideas que en él se exponen en un entorno tan hostil a toda mejora educativa como es la Universidad de Valencia. Hay una serie de hechos que, probablemente, eran tan obvios para el autor del libro que ni siquiera habla de ellos explícitamente, pero que están implícitos en todo cuanto dice, y que permitirían escribir otro libro titulado Lo que no hacen los mejores profesores universitarios, de obligada lectura para quienes han elaborado las diversas normativas a las que estamos sometidos los profesores o tienen la potestad de cambiarlas. Por empezar con un ejemplo sencillo, en la página 69 leemos:

Muchos de los buenos profesores van incluso más lejos, preguntándose ¿Estoy preparado para realizar cambios en sesiones concretas de clase, o en todo el curso, para conectar con mis estudiantes? ¿Cómo puedo elegir ejemplos de lo que les resultará más significativo? ¿Estoy dispuesto a ir parcheando la asignatura conforme progrese - cambiando exámenes, tareas, o lo que hago en clase - para responder a lo que vaya aprendiendo sobre los intereses y conocimientos de mis estudiantes? Con una ingente cantidad de materia a estudiar, ¿puedo elegir ese subconjunto en el que los estudiantes están más interesados?

Un profesor de la Universidad de Valencia perderá el tiempo preguntándose estas cosas, porque la normativa le obliga a presentar a principio de curso un programa detallado con los contenidos de la asignatura y, más aún, un cronograma, palabra que, por fea que suene, no es tan horrible como su significado: es una programación semanal de las clases que el profesor impartirá a lo largo del curso.

Afortunadamente, por ahora no existe ningún control de si un profesor respeta o no sus cronogramas, lo que permite hacerlos en dos minutos y olvidarse de ellos para siempre; pero no deja de ser triste que una normativa tienda a coartar la iniciativa de 
los profesores y disuadirlos con ello de emular a los mejores profesores universitarios. Más grave es el hecho de que, en las encuestas que periódicamente se pasa al alumnado para evaluar la docencia de un profesor, una de las preguntas que se formula es si cabe esperar que éste imparta todo el temario, de modo que los mejores profesores universitarios que siguieran las pautas descritas en el párrafo anterior se encontrarían seguramente con una mala puntuación en este aspecto de la evaluación de su docencia. En resumen, en el párrafo citado está implícito el hecho obvio de que:

Los mejores profesores universitarios no siguen cronogramas ni se someten a un temario prefijado.

Me apresuro a apuntar el hecho, no menos obvio, de que los peores tampoco lo hacen. Un profesor puede no ajustarse a un temario porque honradamente piense que un cambio mejorará el aprovechamiento que sus alumnos obtengan de su asignatura, o también por pura irresponsabilidad, ineptitud o dejadez. Determinar si un profesor sigue o no un programa predeterminado no distingue a los mejores de los peores, sino a los mejores y peores de los mediocres.

Hay otro hecho obvio implícito en el párrafo que he citado, aunque aparece más claramente en otra pregunta formulada un poco antes:

¿Cómo puedo ayudarlos a ver la conexión entre sus preguntas y los asuntos que ya he elegido tratar en el curso?

Los mejores profesores universitarios eligen los contenidos concretos de los cursos que imparten. En particular: 
Los mejores profesores universitarios no se coordinan con otros profesores que impartan su misma asignatura.

Los profesores de la Universidad de Valencia no tenemos técnicamente la obligación de coordinarnos, pero, al final de cada curso, cada departamento ha de elaborar un informe sobre la docencia, en uno de cuyos puntos ha de indicar si los distintos grupos de una misma asignatura se han coordinado en cuanto al temario y el sistema de evaluación, entendiendo que la universidad valora positivamente que exista dicha coordinación. Nuevamente estamos ante la misma tesitura: un profesor puede descoordinarse del resto por ser muy bueno o por ser muy malo. Los intentos de la universidad por promover la coordinación entre grupos no llevan a la excelencia, sino a la mediocridad.

Y, ya que ha aparecido la cuestión de la evaluación, veamos qué dice el libro al respecto (página 180):

Por el contrario, los mejores profesores preparan a los estudiantes para que hagan determinados tipos de trabajo intelectual, no para que sean buenos haciendo exámenes. Los exámenes exigen a los estudiantes que hagan ese trabajo. El objetivo es conseguir congruencia entre los objetivos intelectuales del curso y los que pone a prueba el examen.

$\mathrm{Si}$, tal y como ya hemos comentado, los objetivos intelectuales del curso, lo que el profesor espera que los alumnos aprendan en sus clases, es algo que los mejores profesores universitarios eligen subjetiva y a la vez responsablemente, el párrafo anterior lleva implícito que

los mejores profesores universitarios no evalúan a sus alumnos con exámenes comunes con los grupos impartidos por otros profesores, 
pues la congruencia de la que habla el párrafo extiende la subjetividad en la elección (responsable) de contenidos y metas del curso a la subjetividad en el diseño (responsable) del examen, no sólo por lo que respecta a las preguntas que han de contener, sino también en la forma de valorarlas. Por ejemplo, en el libro se desaconsejan las calificaciones numéricas sistemáticas (pág. 174):

De hecho, la mayoría de ellos [un grupo de profesores que no había sido incluido en el estudio por no haber mostrado indicios de excelencia] defendía que reducir su juicio a una cifra lo convertía en algo más preciso, casi «científico» y, sin duda, «objetivo».

Yo considero que, para merecer un aprobado, no basta con que un alumno se sepa la mitad de la asignatura, sino que ha de saber lo fundamental de la asignatura, de tal suerte que si, por ejemplo, un alumno sabe contestar a todas las preguntas de la primera parte del temario pero no sabe ni lo más básico de la segunda, su nota ha de ser un suspenso, aunque evaluado su examen de 0 a 10 le salga un 6. Por el contrario, si un alumno saca un 4 pero me ha demostrado que tiene claras todas las cosas fundamentales que yo me había propuesto enseñarle, entonces considero que no merecerá un notable ni un sobresaliente, pero sí un aprobado. Éste es el criterio que sigo con los alumnos que voluntariamente prefieren ser evaluados así, en cuyo caso no me molesto en llenar el examen de números y calcular sumas y medias. Pero no tengo nada claro qué sucedería si pretendiera evaluar así a todos mis alumnos, quieran o no. ¿Sería legal? He oído rumores de que es obligatorio que en cada examen esté especificado cuánto vale cada pregunta, y que si no es así ha de entenderse que todas las preguntas puntúan lo mismo. ¿Será eso cierto? Viendo el espíritu de las normas de esta universidad, no me sorprendería. Por si acaso, no está de más añadir un elemento más a la lista de conclusiones: 
Los mejores profesores universitarios no están obligados a poner notas de 0 a 10 con una cifra decimal.

Otro aspecto en torno a la evaluación es cuántos exámenes se hacen y cómo se valoran. El libro explica que los mejores profesores universitarios hacen múltiples exámenes a sus alumnos (pág. 179):

En un sistema así, los estudiantes pueden probar, obtener un resultado regular, recibir realimentación de sus intentos, y volver a probar en el siguiente examen. Lo que entienden y pueden hacer intelectualmente al final del curso es lo que importa, más que cualquier otra cosa.

En la Universidad de Valencia, al menos en mi campus, el de Ciencias Sociales, los profesores tenemos prohibido hacer exámenes parciales (salvo que estén establecidos oficialmente, lo que no depende en absoluto del profesor). Al parecer, en la comisión donde se tomó este acuerdo había algunos profesores sensatos que sabotearon la norma al lograr que se permitiera la realización de "ejercicios de evaluación continua", cuya diferencia con los exámenes parciales es etérea, lo que nos da cierto juego; pero, en cualquier caso, está prohibido reservar un aula fuera del horario de clase para tener un tiempo razonable para hacer un examen.

Un examen de calidad, donde no se pretenda aprobar a los alumnos que sepan la mitad, sino a los alumnos que sepan lo básico, ha de tener cierta extensión. Si un examen ha de caber en el tiempo de una clase (dos horas), hay que contar con un margen de, digamos, media hora para empezar y recoger, con lo que el tiempo útil se reduce a hora y media, y un examen que un alumno medio pueda hacer en hora y media ha de ser un examen que un buen alumno (que no necesite pararse mucho a pensar o rehacer cálculos erróneos) pueda despachar en tres cuartos de hora, y eso reduce el examen a cuatro o cinco preguntas no muy extensas, que de ningún modo 
pueden indicar al profesor si el alumno ha asimilado los aspectos básicos del curso. De acuerdo con el libro (pág. 169):

Exámenes y calificaciones se convierten en una forma de ayudar a los estudiantes a comprender su progreso en el aprendizaje.

Pero difícilmente le puede ayudar a ningún estudiante suspender un examen si el profesor sólo tiene derecho a hacerle un único examen al final del curso, como sucede en la mayoría de las asignaturas en la Universidad de Valencia (al menos en mi campus), o si sólo puede hacerle exámenes paupérrimos por su brevedad que no indican nada realmente. En resumen:

Los mejores profesores universitarios no tienen prohibido examinar a sus alumnos.

No sé si habrá almas cándidas que crean que los inconvenientes que aquí estoy señalando se corregirán con la reforma de los planes de estudio que actualmente está en proceso de ensayo. Si es así me remito a las páginas 194-195 del libro:

Quizá el segundo mayor obstáculo sea la noción simplista de que una buena docencia es sólo una cuestión de técnica. La gente que cree en esa idea tal vez esperase que este libro le proporcionase unos cuantos trucos fáciles para poder aplicarlos en sus aulas. [...] A menudo, la mejor enseñanza es tanto una creación intelectual como un arte escénica. [...] En pocas palabras, debemos exprimirnos los sesos para descubrir qué significa aprendizaje en nuestras disciplinas y cómo cultivarlo y reconocerlo de la mejor manera. Para esa tarea no necesitamos expertos de la rutina que conocen todos los procedimientos correctos, sino expertos de la adaptación que pueden aplicar principios fundamentales a cualquier situación y clase de estudiantes que es probable que podamos encontrar, reconociendo cuándo es, tanto posible como necesario, inventar algo, y que no hay una única «mejor 
manera» de enseñar. Si nos vamos a beneficiar del ingenio y las prácticas de profesores extraordinarios, debemos ir más allá del escenario de «sabedores de lo aceptado» limitándonos a esperar respuestas correctas -trucos del oficio- que podamos usar a ciegas.

La reforma educativa en ciernes no es más que institucionalizar una serie de trucos del oficio que pretenden ser usados a ciegas: cronogramas, eceteeses (consistentes en poner en un papel, no sé para qué, cuántas horas ha de soñar el alumno con la asignatura mientras duerme, y cosas así), establecer unas horas de tutorías iguales para todos (aunque algunos alumnos necesiten más, otros menos, y otros no las necesiten en absoluto), controlar la evaluación, la docencia, y, en suma, restringir al máximo el margen de decisión y de adaptación del profesor, sin tener en cuenta en absoluto la naturaleza de la materia que imparta o las características de los alumnos a los que se enfrenta. En resumen:

Los mejores profesores universitarios no son androides teledirigidos por una normativa omnímoda.

A la luz de estas consideraciones, resulta irónica la discrepancia entre los criterios del libro recomendado por la carta de la rectora o del rector y los de la carta que recomienda el libro, en la cual leemos estos párrafos, que me he permitido traducir al castellano por si me lee alguien de fuera (el resaltado en negritas es mío, el pleonasmo no):

El análisis sobre el trabajo de los grupos de innovación de nuestra universidad nos pone de manifiesto que probablemente la innovación con mayor potencial de cambio y mejora se sitúa en la capacidad de tomar decisiones y actuar de forma coordinada en asuntos relativos a estrategias y formas de enseñanza por parte de un grupo de profesores y profesoras [sic]. Y esto nos sitúa ante el reto de ir cambiando 
progresivamente las creencias, los hábitos, los supuestos, en suma, una cultura de la docencia muy anclada en la idea del individualismo del docente (basada en la idea de que enseñar significa fundamentalmente "dar clase"), hacia una cultura basada en la consideración de la docencia como responsabilidad compartida.

Estoy completamente de acuerdo en que enseñar no significa fundamentalmente dar clase. La sintaxis no deja claro si lo que está basado en la idea de que "enseñar significa dar clase" es la cultura de la docencia o la idea del individualismo del docente, pero voy a suponer que es lo primero y así podemos dejar de lado este punto en el que no hay discrepancia y centrarnos en el individualismo. ¿Por qué es una mejora educativa que un profesor no actúe individual sino coordinadamente? Cuando se habla de coordinar a un grupo de profesores, ¿hablamos de profesores buenos o mediocres? Si son buenos, ¿qué ganamos coordinándolos?, si son mediocres, ¿cabe esperar que de la mediocridad acumulada surja la genialidad?, y si hay de buenos y de mediocres, ¿no es ingenuo esperar que sea la mediocridad la que se impregne de genialidad y no la genialidad la que termine asfixiada por la mediocridad?

En el epílogo del libro de Bain se dan ideas sobre cómo mejorar la calidad de la docencia, pero la palabra coordinación no aparece en ningún momento. Al contrario, toda la discusión parte de la tesis implícita de que los buenos profesores universitarios son como pintores que han logrado una estilo personal, adaptado íntimamente a su propia idiosincrasia, en suma, un estilo individual, con el que consiguen conectar eficientemente con su público, un estilo del que se puede tratar de aprender, de extraer ideas, compartirlas y difundirlas, pero nunca copiar sin más.

Hacia 1435 Donatello estaba esculpiendo una tribuna para los cantores de la catedral de Florencia, y en la pared de enfrente hacía lo propio Lucca della Robbia. Eran los dos mejores escultores de la época y trabajaban uno frente al otro. ¿Acaso se 
coordinaron? No. Los dos hicieron trabajos espléndidos, apropiados para el lugar y acordes con el entorno, pero el estilo de uno es completamente opuesto al del otro. ¿Hubiera sido sensato que los florentinos que financiaban la catedral les hubieran exigido coordinación? ¿No es evidente que cualquier intento de adaptar mutuamente sus criterios habría ido en detrimento de su genialidad? Dicen que Beethoven se lamentaba de no ser capaz de componer una fuga como las de Bach, y compuso varias fugas, pero ninguna de ellas tiene el genio de Bach. Todas tienen el genio de Beethoven. ¿Hubiera sido razonable exigir a Chaikovsky que se ciñera a las formas clásicas, cuando él mismo se declaraba incapaz de hacerlo? Cualquiera que entienda realmente que "enseñar no significa meramente dar clase" (y tenga una idea mínimamente aproximada de qué es realmente enseñar) comprenderá por sí mismo la analogía entre estos ejemplos y el problema de la docencia.

Lograr una docencia de calidad es un problema abierto, como decidir la mejor política económica para un país o luchar contra el cáncer. No hay nadie que pueda señalar objetivamente el camino correcto para enfrentarse al problema. Lo único que puede hacerse ante un problema así es probar, experimentar, alentar las iniciativas, evaluarlas, pero nunca coartarlas (salvo que fracasen). La docencia es investigación, y la investigación es esencialmente individual: consiste en que cada individuo aprenda de los demás las ideas que sea capaz de asimilar y aporte a los demás las ideas que sea capaz de generar. La única coordinación posible es la que surge de la afinidad: la que surge cuando investigadores en una misma área coinciden espontáneamente en orientar su investigación en una misma dirección y, aun así, la coordinación no puede consistir sino en el intercambio de experiencias e ideas, pero jamás en el compromiso de renunciar a los propios criterios para aplicar otros ajenos, pues de tal perversión no puede nacer sino una torpe criatura de remiendos como la creada por la doctora Victoria o el doctor Víctor Frankenstein. 